\title{
Effects of cisapride, a new gastrointestinal prokinetic substance, on interdigestive and postprandial motor activity of the distal oesophagus in man
}

\author{
A J P M SMOUT, J W BOGAARD, A C GRADE, O J TEN THIJE, \\ L M A AKKERMANS AND P WITTEBOL \\ From the Departments of Gastroenterology and Surgery, Utrecht University Hospital, Utrecht, \\ The Netherlands
}

SUMmary Cisapride is a newly developed substance that stimulates gastrointestinal motility, possibly enhancing acetylcholine release in the gut wall. The aim of our study was to investigate the effect of cisapride on oesophageal motor function in man. In a blind fashion and in random order six healthy volunteers received cisapride $(0.5 \mathrm{mg} / \mathrm{h}$ intravenously, preceded by a three day oral loading at $10 \mathrm{mg}$ tid) and matching placebo. Oesophageal contractions and lower oesophageal sphincter pressure were constantly recorded during a complete cycle of the interdigestive migrating motor complex and during two and half hours after a mixed test meal. Cisapride did not disturb the interdigestive migrating motor complex. In the fasting state the lower oesophageal sphincter pressure showed considerable interdigestive migrating motor complex phase-related variations, whereas amplitude and duration of the oesophageal contractions did not. In the dosis used cisapride was found to increase lower oesophageal sphincter pressure in the interdigestive and in the late postprandial state, but to have no effect in the early postprandial period. Amplitude and duration of oesophageal contractions were not affected by cisapride.

Cisapride ( $\mathrm{R}$ 51619, Janssen Pharmaceutica) is a newly developed compound (Fig. 1) that stimulates gastrointestinal motility, most likely through facilitation of acetylcholine release from myenteric nerves. ${ }^{12}$ Unlike metoclopramide and domperidone the substance possesses no antidopaminergic properties. Unlike acetylcholine analogues, such as betanechol, and cholinesterase inhibitors, such as neostigmine, cisapride appears to have no extragastrointestinal effects and to have no effect on gastrointestinal secretion. Potentially, the substance could be useful in a diversity of pathological conditions. If cisapride would increase the lower oesophageal sphincter pressure, in man and under steady-state conditions, the substance might become of use in the treatment of gastro-oesophageal reflux and reflux oesophagitis. In this perspective a study was undertaken to investigate the effect of cisapride on the lower oesophageal sphincter pressure and on

Address for correspondence: A J P M Smout. Dept of Gastroenterology. Utrecht University Hospital, PO Box 16250, 3500 CG Utrecht. The Netherlands.

Received for publication 1 June 1984 oesophageal motility in healthy human subjects. It was realised that the lower oesophageal sphincter pressure is not constant. In the fasting state the lower oesophageal sphincter pressure shows substantial fluctuations which appear to be related to the interdigestive migrating complex. ${ }^{34}$ Furthermore, the lower oesophageal sphincter pressure changes after consumption of a meal, the effect depending on the composition of the meal. ${ }^{5-7}$ Whether amplitude and duration of the contractions in the oesophageal body are likewise related to motility patterns in the upper gut is not known. Therefore, the study was designed such that the effect of cisapride on oesophageal contractions and lower oesophageal sphincter pressure could be

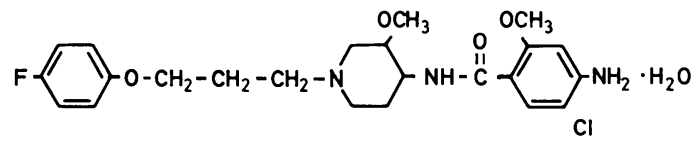

Fig. 1 Structural formula of cisapride. 
measured continuously in the various interdigestive and postprandial motor phases.

\section{Methods}

\section{SUBJECTS}

Six healthy male volunteers (aged 22-33 years) without any history of gastrointestinal disease were studied. They all gave informed consent. The study was approved by the ethical committee of the Utrecht University Hospital. Each subject participated in two experiments in which either placebo or cisapride was administered in a double blind and randomised fashion. These two experiments were performed on separate days with intervals of at least five days.

\section{TECHNIQUES OF RECORDING}

Intraluminal pressures in distal oesophagus, lower oesophageal sphincter, gastric fundus, distal antrum, and proximal duodenum were recorded with two manometric assemblies (Fig. 2). Antral and duodenal pressures were recorded with an intraluminal strain gauge transducer assembly (Gaeltec) which was positioned under fluoroscopic control. The pressures at the proximal three recording sites were measured with a perfused sleeve catheter assembly, constructed according to Dent. ${ }^{8}$ The sleeve sensor $(5 \mathrm{~cm}$ long) was positioned in the lower oesophageal sphincter, guided by the

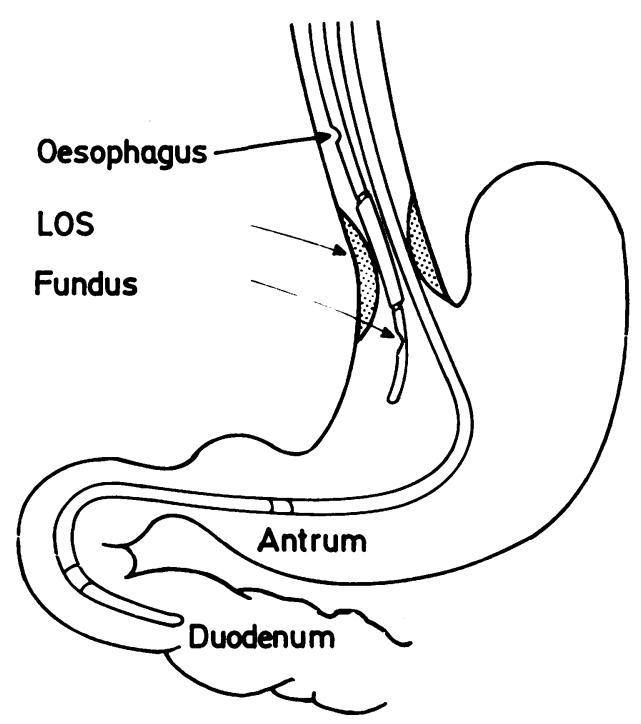

Fig. 2 Positions of sleeve catheter assembly and strain-gauge transducer assembly used to record intraluminal pressures. pressure recordings, and the assembly taped to the nose. Side-hole recording orifices at $10 \mathrm{~cm}$ above and at $5 \mathrm{~cm}$ below the middle of the sleeve sensor measured intraluminal oesophageal pressure and fundic pressure respectively. The catheters were constantly perfused with distilled water at a rate of 1 $\mathrm{ml} / \mathrm{min}$, using a low-compliance perfusion system. ${ }^{9}$ The catheters were connected to external pressure transducers (Hewlett Packard 1280). All signals were recorded on paper using a 6-channel ink writer (Gould) with a paper speed of $25 \mathrm{~mm} / \mathrm{min}$. In addition, the signals were recorded on magnetic tape using a Racal-Store 7 with a tape speed of 15/16 inch $/ \mathrm{s}(2.38 \mathrm{~cm} / \mathrm{s})$.

\section{CONDUCT OF THE EXPERIMENTS}

On the three days preceding each experiment the subjects took $30 \mathrm{mg}$ of cisapride $(10 \mathrm{mg}$ tid $)$, or placebo, daily as tablets with identical appearance. Before the experiments the subjects fasted overnight. The pressure transducer assemblies were introduced through the nose. In each arm an intravenous cannula was inserted. Through one cannula cisapride or isotonic saline solution was infused at a constant rate. The dosage of cisapride was $0.5 \mathrm{mg} / \mathrm{h}$. The other cannula was used for blood sampling. The subjects were studied while resting quietly in the supine position. The recordings obtained during the first 60 minutes after insertion of the pressure transducer assemblies and cannulae were not considered.

A complete cycle of the interdigestive migrating motor complex involving the lower oesophageal sphincter, stomach, and duodenum was recorded. When an interdigestive migrating motor complex cycle occurred in the duodenum but not in lower oesophageal sphincter and stomach, this cycle was disregarded and the next one awaited. Blood samples for determination of cisapride concentration were taken in phase I, in phase II, and in phase III of the interdigestive migrating motor complex. Plasma was separated from the heparinised samples and immediately stored at $-20^{\circ} \mathrm{C}$.

At the beginning of the next phase I the subjects consumed a test meal. This meal consisted of a slice of white bread with $50 \mathrm{~g}$ of cheese, one boiled egg, and $200 \mathrm{ml}$ of skimmed milk. This meal contained $30 \mathrm{~g}$ of protein, $20 \mathrm{~g}$ of fat, and $24 \mathrm{~g}$ of carbohydrates, corresponding to $1690 \mathrm{~kJ}$ (400 kcal). After ingestion of the meal recording was continued for $2.5 \mathrm{~h}$. Blood samples were taken at 60 and 150 minutes after completion of the meal.

ANALYSIS

All curves were interpreted before breaking the code. Phases of the interdigestive migrating motor 
complex as occurring in the antrum were defined as follows: phase I was the period of motor quiescence, phase II the period with contractions giving rise to pressure changes of $1.3 \mathrm{kPa}(10 \mathrm{~mm} \mathrm{Hg})$ or more and occurring with a frequency of more than two per 10 minutes, and phase III was a burst of rhythmic high-amplitude pressure waves. Phase II was further divided into three subphases. Phase II-1 was defined as the first 15 -min period, and phase II-3 as the last 15-min period of phase II. Consequently, phase II-2 had a variable duration. Mean end-expiratory lower oesophageal sphincter pressure in each of the interdigestive phases and in each of the five halfhour postprandial periods was calculated by determining the mean difference between the line connecting all end-expiratory lower oesophageal sphincter pressures and the fundic pressure baseline. This was done from the chart recordings by means of a digitiser and a computer. Samples were taken at 60 ms (real time) intervals. Spontaneous and swallowinduced lower oesophageal sphincter relaxations were not taken into account. Mean amplitude and duration of five oesophageal contractions in each of the motor phases were determined as follows. Signal portions from each of the motor phases were replayed from tape and written on paper, using a paper speed of $375 \mathrm{~mm} / \mathrm{min}$. Using pencil and ruler, the amplitude of the oesophageal contraction waves was measured, taking the mean end-expiratory oesophageal pressure as baseline. The duration of the contraction waves was measured from the onset of their rapid upward deflection to the end of their rapid downward deflection.

Cisapride plasma concentrations were determined at the laboratories of Janssen Pharmaceutica (Beerse, Belgium), using high-performance liquid chromatography.

STATISTICAL EVALUATION

Results are expressed as mean \pm SEM. Differences between placebo and cisapride values were evaluated by paired Student's $t$ tests and by analysis of variance.

\section{Results}

Two of the volunteers experienced transient abdominal cramps and some diarrhoea shortly after the ingestion of the first tablet of cisapride. During the following days and during intravenous infusion of cisapride no side-effects were noted. In each subject the cisapride plasma concentrations were constant during the course of the experiment. The mean cisapride level was $37 \cdot 1 \pm 5 \cdot 7 \mathrm{ng} / \mathrm{ml}$.

In all experiments (placebo and cisapride) interdigestive motor complexes occurred in lower oesophageal sphincter, stomach, and duodenum (Fig. 3). In one of the placebo experiments, however, the interdigestive complex occurring in lower oesophageal sphincter and stomach did not include a typical phase III activity, whereas phase III was normally present in the duodenum. In the interdigestive state, the lower oesophageal sphincter pressure clearly showed interdigestive migrating motor complex phase-related variations. In the placebo experiments mean lower oesophageal sphincter pressure rose from $1.93 \pm 0.50 \mathrm{kPa}$ $(14.5 \pm 3.5 \mathrm{~mm} \mathrm{Hg})$ in phase I to $3.87 \pm 1.01 \mathrm{kPa}$ $(29.0 \pm 7.6 \mathrm{~mm} \mathrm{Hg})$ in phase III. The postprandial lower oesophageal sphincter pressure was rather constant at a level comparable with that measured in interdigestive migrating motor complex phase I (mean postprandial lower oesophageal sphincter pressure in the placebo experiments $1.97 \pm 0.45 \mathrm{kPa}$ $(14.8 \pm 3.4 \mathrm{~mm} \mathrm{Hg})$.

Cisapride increased the interdigestive lower oesophageal sphincter pressure, the increase varying from $36.4 \pm 13.4 \%$ (phase I) to $27.9 \pm 10.4 \%$ (phase II-3). The effect reached statistical significance in phases I, II-2 and II-3 (paired $t$ tests). The overall effect in the interdigestive state was highly significant ( $p<0 \cdot 01$, analysis of variance). In the early postprandial periods no effect of cisapride on the lower oesophageal sphincter pressure was observed, but later after the meal cisapride tended to increase the lower oesophageal sphincter pressure. This effect was statistically significant in the last postprandial half-hour period (121-150 $\mathrm{min})$, in which the increase was $37 \cdot 4 \pm 14 \cdot 3 \%$ (Fig. 4).

The amplitude and duration of the oesophageal contractions did not show any significant variations in time. Mean amplitudes of interdigestive and postprandial oesophageal contractions were $6.29 \pm 0.99$ and $6.87 \pm 0.89 \mathrm{kPa}(47.2 \pm 7.4$ and $51.5 \pm 6.7 \mathrm{~mm} \mathrm{Hg}$ ), respectively (placebo values). Mean durations of interdigestive and postprandial oesophageal contractions were $3 \cdot 30 \pm 0 \cdot 40$ and $3 \cdot 15 \pm 0 \cdot 37 \mathrm{~s}$. Cisapride had no significant effect on amplitude and duration of the oesophageal contractions (Fig. 5).

\section{Discussion}

In the present study upper gastrointestinal motility in healthy human subjects was recorded during prolonged periods of time, with and without administration of a new prokinetic substance, cisapride. Although this study had not been designed to investigate the effect of cisapride on the interdigestive migrating motor complex in detail, it can be concluded that chronic administration of cisapride does not disturb the cyclic interdigestive 

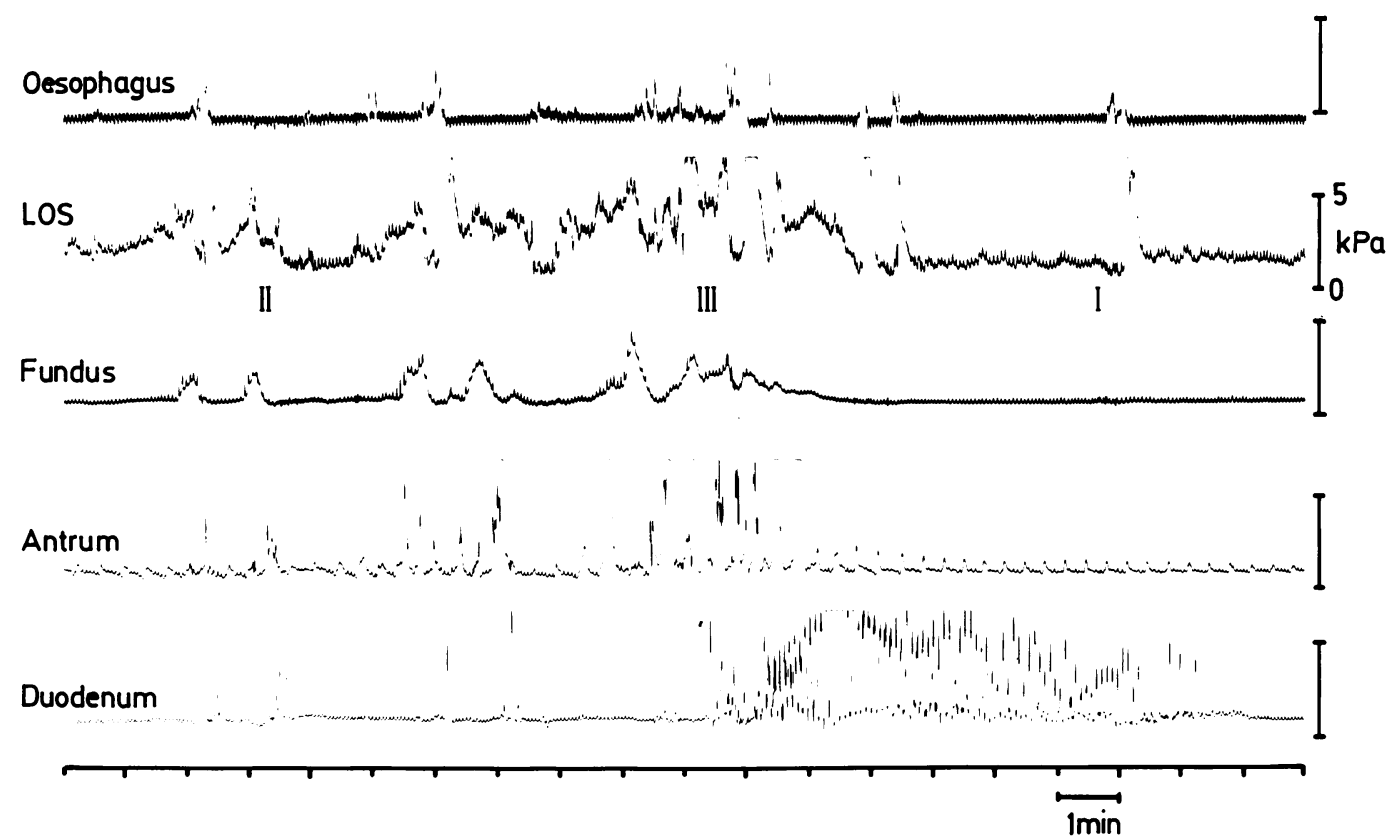

Fig. 3 Example of intraluminal pressure signals recorded from oesophageal body, lower oesophageal sphincter, fundus, antrum and duodenum in the fasting state. Highest lower oesophageal sphincter pressure is present in phase III, lowest in phase I. The interdigestive migrating motor complex phases in the lower oesophageal sphincter concur with those in fundus and antrum. $1 \mathrm{kPa}=7.5 \mathrm{mmHg}$.

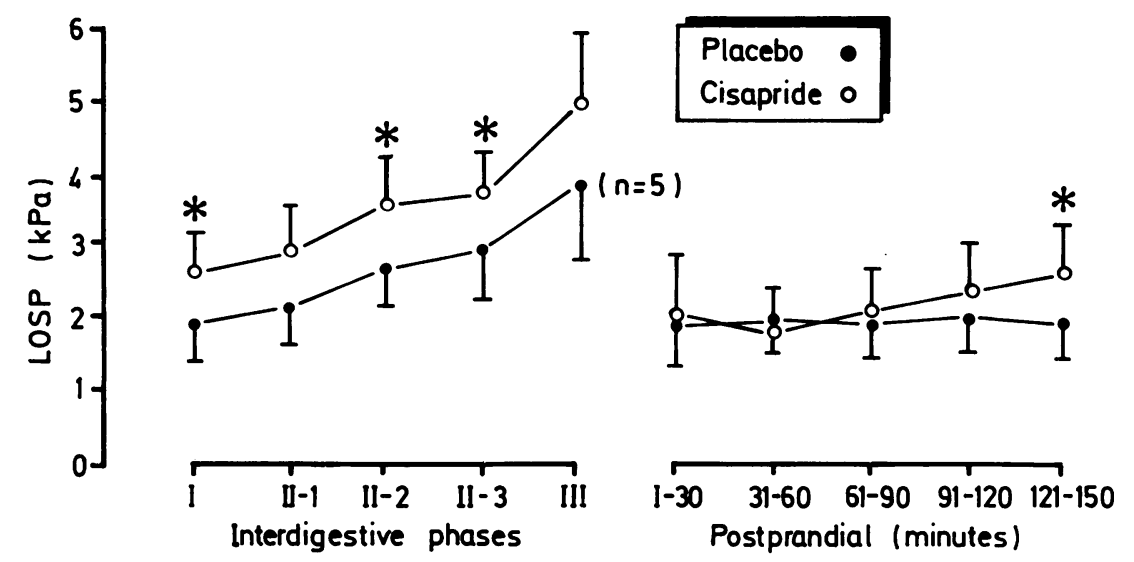

Fig. 4 Mean lower oesophageal sphincter pressure $( \pm S E M)$ in six healthy subjects, during administration of placebo and cisapride. $\star$ statistically different from placebo, $p<0.05$ (paired test). $1 \mathrm{kPa}=7.5 \mathrm{mmHg}$. 

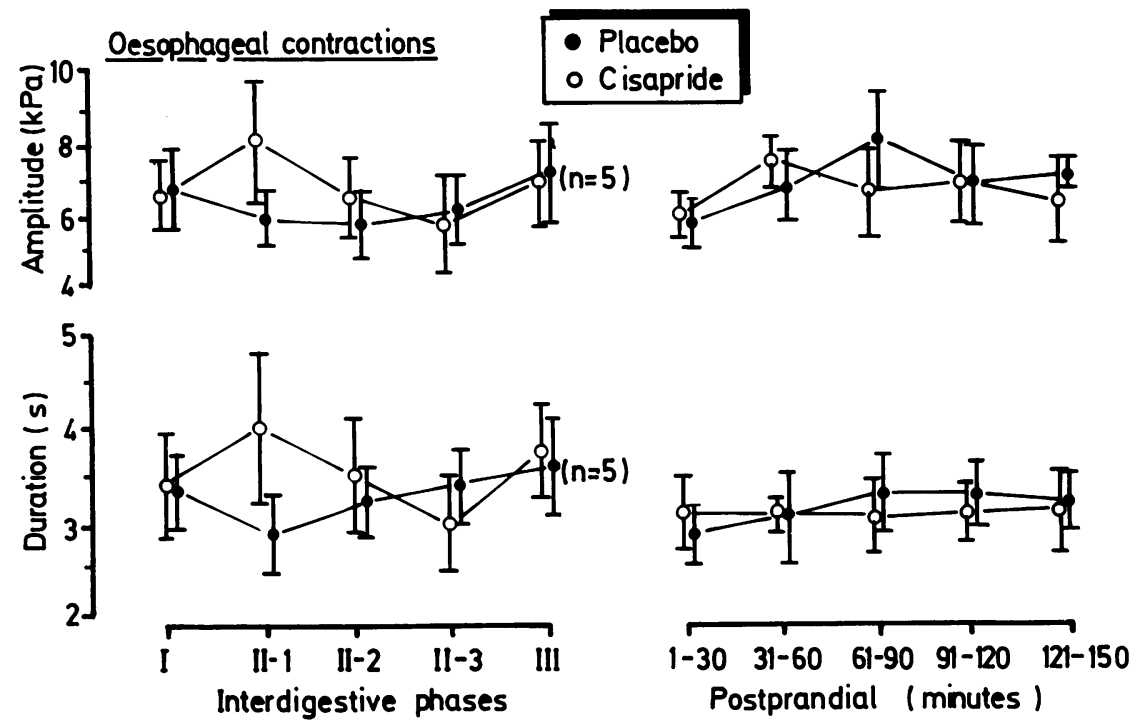

Fig. 5 Mean amplitude and duration ( \pm SEM) of oesophageal contractions in six healthy subjects, during administration of placebo and cisapride. $1 \mathrm{kPa}=7.5 \mathrm{mmHg}$.

motility pattern. In contrast, administration of an intravenous bolus injection of $0.63 \mathrm{mg} / \mathrm{kg}$ of cisapride in fasting dogs temporarily disrupted the normal interdigestive migrating motor complex pattern. ${ }^{10}$ The cisapride plasma concentrations reached in those experiments, however, are not comparable with the relatively low concentrations established in our human volunteers. In fact, the steady-state plasma cisapride concentration of $37 \cdot 1 \pm 5.7 \mathrm{ng} / \mathrm{ml}$ reached in this study is somewhat lower than was intended; it is below the peak concentration obtained after a single oral dose of $10 \mathrm{mg}$.

Amplitude and duration of oesophageal contractions were not increased by cisapride. This finding is not in keeping with a recent study in which intravenous injection of $8 \mathrm{mg}$ of cisapride was found to increase the amplitude of oesophageal contractions. ${ }^{11}$ Again, differences in the plasma cisapride concentrations obtained in these two studies probably explain the divergence of the results.

The present study confirmed that the human lower oesophageal sphincter participates in the interdigestive migrating motor complex. ${ }^{34}$ Both with placebo and with cisapride phase III lower oesophageal sphincter pressure was about twice as high as phase I lower oesophageal sphincter pressure. These observations clearly show that studies of fasting lower oesophageal sphincter pressure have only limited value when the interdigestive migrating motor complex is not taken into account.' In contrast, amplitude and duration of oesophageal contractions did not exhibit interdigestive migrating motor complex phase-related variations, nor did the postprandial values differ from the interdigestive values. These hitherto undescribed observations imply that in studies on the characteristics of oesophageal contractions interdigestive and postprandial motility patterns can be disregarded.

Cisapride was found to increase the interdigestive lower oesophageal sphincter pressure, an effect that could be expected on the basis of its mechanism of action. It is not clear, however, why cisapride had no effect of the lower oesophageal sphincter pressure in the early postprandial period. Apparently, in the early postprandial state one (or several) of the hormonal and neuronal mechanisms elicited by the meal antagonise the stimulatory effect of cisapride on the lower oesophageal sphincter pressure.

It is possible that cisapride will be found to reduce gastro-oesophageal reflux because the substance increases the lower oesophageal sphincter pressure and enhances gastric emptying. ${ }^{1}{ }_{11}$ The results of our study suggest that cisapride might have a greater effect on fasting than on post-prandial reflux. Studies of the differential effects of drugs on fasting and postprandial reflux are needed as supine - that is, fasting, and upright - that is, postprandial, reflux play different roles in the development of refluxoesophagitis. ${ }^{12}$ The results of medical treatment of refluxoesophagitis, though improved greatly in 
recent years, are still far from ideal. Detailed knowledge of the fasting and postprandial motor effects of all available drugs might improve these results by providing the basis for a rational selection of drugs and an optimal timing of their administration.

\section{References}

1 Schuurkes JAJ, Akkermans LMA, van Nueten JM. Stimulating effects of cisapride on antroduodenal motility in the conscious dog. In: Roman C, ed. Gastrointestinal motility. Lancaster: MTP Press, 1984: 95-102.

2 Van Nueten JM, van Daele PGH, Reyntjens A, Janssen PAJ, Schuurkes JAJ. Gastrointestinal motility stimulating properties of cisapride, a non-antidopaminergic non-cholinergic compound. In: Roman C, ed. Gastrointestinal motility. Lancaster: MTP Press, 1984: 513-20.

3 Lux G, Lederer P, Femppel J, Rösch W, Domschke W. Spontaneous and 13-NLE-motilin-induced interdigestive motor activity of esophagus, stomach and small intestine in man. In: Christensen J, ed. Gastrointestinal motility. New York: Raven Press, 1980: 269-78.
4 Dent J, Dodds WJ, Sekiguchi T, Hogan WJ, Arndorfer RC. Interdigestive phasic contractions of the human lower esophageal sphincter. Gastroenterology 1983; 84: 453-60.

5 Babka JC, Castell DO. On the genesis of heart-burn the effects of specific foods on the lower esophageal sphincter. Am J Dig Dis 1973; 18: 391-7.

6 Nebel OT, Castell DO. Lower esophageal sphincter pressure changes after food ingestion. Gastroenterology 1972; 63: 778-83.

7 Nebel OT, Castell DO. Inhibition of the lower oesophageal sphincter by fat - a mechanism for fatty food intolerance. Gut 1973; 14: 270-4.

8 Dent J. A new technique for continuous sphincter pressure measurement. Gastroenterology 1976; 71: 263-7.

9 Arndorfer RC, Steff JJ, Dodds WJ, Lineham JH, Hogan WJ. Improved infusion system for intraluminal esophageal manometry. Gastroenterology 1977; 73: 23-7.

10 Schuurkes JAJ, van Nueten JM. Control of gastroduodenal coordination: dopaminergic and cholinergic pathways. Scand J Gastroenterol 1984; 19: suppl 92: 8-12.

11 Corazziari E, Scopinaro F, Bontempo I et al. Effect of R51619 on distal oesophageal motor activity and gastric emptying. Ital J Gastroenterol 1983; 15: 185-6.

12 DeMeester TR, Wang CI, Wernley JA et al. Technique, indications and clinical use of 24-hour pH-monitoring. J Thorac Cardiovasc Surg 1980; 79: 656-70. 